\title{
PERMANENT DEFORMATION MODELS FOR A GRANULAR MATERIAL USED IN ROAD PAVEMENTS
}

\author{
I. Pérez ${ }^{*}$ L. Medina \\ Universidade da Coruña. E. T. S. I. Caminos, Campus de Elviña, 15071 A Coruña, Spain \\ M. G. Romana \\ Universidad Politécnica de Madrid. E. T. S. I. Caminos, Ciudad Universitaria, 28040 Madrid, Spain
}

\begin{abstract}
This paper analyses the permanent deformation performance of an unbound granular material that has been subjected to repeated triaxial loads. The study focuses on the evolution of the cumulative strain and includes a classification of the specimens according to the shakedown concept. This was done by fitting models that express the cumulative strain to cyclic loads and stress level. The predictions of the models were not absolutely perfect. The results with the granular material were not satisfactory enough to warrant their use in a low traffic road pavement section in Galicia (Spain).
\end{abstract}

Keywords: Granular material; permanent deformation; models, rutting

\section{Introduction}

The budget earmarked for road pavement construction exceeds $25 \%$ of the total resources dedicated to the construction of roads all over the world. Some of the most frequently used pavements are the types designated as flexible and semi-flexible which are composed of granular layers that provide the support for bituminous layers. Moreover, granular layers may be employed as bases for rigid pavements if materials of non-erosional quality are being used.

Thus, granular layers play a very important role in the behaviour of pavements. In fact, the design life of the pavement has much to do with the quality and response of the granular layers. Nevertheless, owing to a combination of the relatively low cost of these materials, their heterogeneous nature and the limited effort required to manufacture them, they have received little attention in terms of predicting their structural performance.

Even so, several researchers have obtained prediction models for permanent deformation, yet none of these have been fully incorporated into the technical guidelines for pavement structural design in most countries. Therefore, the objective of this article is to examine the applicability of the main 
models that predict cumulative permanent deformation depending on the number of load cycles and level of stress. Thus, this paper aims to incorporate these models into the analytical structural design of pavements in Spain.

\section{Granular material and preparation of specimens}

The unbound material tested was crushed granitic stone, frequently used as a subbase for road pavements in the region of Galicia. Its grading curve (fig. 1) falls within the limits corresponding to the granular material designated as ZA25, defined in the "General technical specifications for works on roads and bridges" in Spain [1]. Table 1 shows the results of other characterisation tests, all of which fulfil the conditions laid down in the above-mentioned specifications, with the exception of the Los Angeles Coefficient, which, with a value of $37 \%$, is slightly higher than the $35 \%$ specified as the maximum.

The laboratory sample was prepared using a special cylindrical aluminium mould consisting of two pieces which allowed it to be opened lengthwise for easy removal of the compacted sample. In the first part of the test, four laboratory samples of granular material were compacted in the mould (without a membrane), and their dry densities and optimum moistures were obtained. Afterwards, the specimens that were to be subjected to the triaxial test were fabricated. Before compacting the material, the first membrane was attached to the wall of the container by applying a vacuum between the mould and the membrane. Compaction was carried out in three layers, with a vibrating hammer - 20 seconds for each layer. The laboratory samples were compacted at the optimum moisture content $(6.4 \%)$ to reach the maximum dry density $\left(2.3 \mathrm{~g} / \mathrm{cm}^{3}\right)$. After compaction was completed and before implementing the actual dynamic tests, the specimens were held for 24 hours in a humid chamber at a temperature of $20^{\circ} \mathrm{C}$ with a relative humidity of $95 \%$.

\section{The triaxial apparatus and stress path}

The tests were carried out with a dynamic triaxial apparatus, consisting essentially of a main unit containing the axial load system generator and a removable chamber. Three controllers are used to generate the chamber and back pressure, as well as the air pressure, in the partially saturated samples. The most commonly used chamber fluid is deaerated water, although with laboratory samples of granular material, oil can also be used. The analogical signals sent from the transducers 
and load cell are received by a module where they are transformed into digital signals. The system has a converter for the digital signals sent from the computer. This system is located in the main unit and facilitates the transmission of the user's orders to the motor controller. The whole system is controlled by a PC which is equipped with the appropriate software allowing for easy and accurate communication between the user and the triaxial apparatus. This software makes it possible to select the type of test to be performed as well as all the parameters, stress paths, data to be stored, etc. This apparatus is limited to laboratory samples with a maximum diameter of 100 $\mathrm{mm}$ and a height of $200 \mathrm{~mm}$. Moreover, the apparatus allows the laboratory sample to be subjected to cyclic axial deviatoric stresses, but it is not feasible to vary the confining radial stresses at the same time.

The stress path was selected according to the stress produced in a section of pavement in use in Spain. To be exact, section 4131 of the "Regulations on pavement sections and pavement structural layers" [2] was considered, conforming to $100 \mathrm{~mm}$ of asphalt mixture material and 200 mm of granular material resting upon a sub-grade of type E3 (cement stabilised soil with a CBR greater than 20). Consequently, the principal stresses $\left(\sigma_{1}\right.$ and $\left.\sigma_{3}\right)$ were calculated in the pavement section, with a single axle load of $130 \mathrm{kN}$ using single tires having a tire pressure of $900 \mathrm{kPa}$ and a contact area of $15.16 \mathrm{~cm}$ in the radius. The calculation was made with a three-dimensional model of the section and a programme of finite differences (FLAC 3D)[3]. The stresses were found at different points in the granular material. The results were expressed in terms of deviator stress $q=\sigma_{1}-\sigma_{3}$ and mean normal stress $p=\left(\sigma_{I}+2 \sigma_{3}\right) / 3$ (Figure 2). For this reason, it was decided to subject the laboratory samples to eleven different stress paths. With this task, dynamic tests of $2 \times 10^{5}$ load cycles were carried out with a sinusoidal wave frequency of $1 \mathrm{~Hz}$ (Table 3).

\section{Permanent deformation models}

The permanent deformation models employed in this paper were the Sweere model [4]; the Wolff model [5]; the exponential law model [6] and the Paute model [7] (Table 2). The first three are nonlinear models that predict the permanent deformation $\varepsilon_{1 p}(\%)$ as a function of the number of cycles $(N)$. The Paute model also predicts permanent deformation $\varepsilon^{*} 1 p(\%)$ as a function of $N$; but subtracting the permanent deformation of the first 100 cycles. In the Paute model, parameter $A$ is 
considered to be the limit value of the accumulated permanent axial deformation when $N$ tends to infinity. On the other hand, according to Paute et al [7] when parameter $B$ is negative or excessively small, it should be considered a "practical value" as the limit of the cumulative permanent axial deformation. In practice, the authors recommend comparing the value of $A$ with the twice the value of the cumulative permanent deformation corresponding to the first 20000 cycles, which is equal to 2 [ $\left.\left.\varepsilon_{1 p}^{*} 20000 \%\right)\right]$. When $A$ is greater than $\left.2\left[\varepsilon_{1 p}^{*} 20000 \%\right)\right]$ the latter should be taken as the "practical value". Also studied were the "Second part of the Paute model" [7] and the Lekarp model [8]; [9]. These models predict permanent deformation as a function of the stress (Table 2).

\section{Classification of granular material using the "shakedown concept"}

For the purpose of classifying the structural response of the material to the applications of load cycles, the criterion proposed by Werkmeister et al [10] was used. According to this criterion, a material would fall into one of the following three cases:

- "Range A", (Plastic Shakedown), when the cumulative permanent strain rate $\left(\varepsilon_{1 p}(\%) / N\right)$ decreases rapidly until it reaches a state of equilibrium. The deformation is entirely resilient and does not produce permanent deformations. The material does not reach failure.

- "Range B", (Plastic Creep), when the cumulative permanent strain rate is either decreasing or constant. Although the deformation is not entirely resilient, permanent deformation is acceptable. For a great number of load cycles the material may reach failure.

- "Range C", (Incremental Collapse), when the cumulative permanent strain rate increases very rapidly, failure occurs with a relatively small number of load cycles.

In figure $3, \varepsilon_{1 p}(\%) / N$ versus $\varepsilon_{1 p}(\%)$ is represented for the eleven stress conditions in which the dynamic triaxial tests were carried out. This figure shows that in the four curves with stress paths $\mathbf{P 1}, \mathbf{P 2}, \mathbf{P} 3$ and $\mathbf{P 6}$, as the aforementioned rate decreases rapidly, the cumulative permanent axial strain undergoes a relatively minor increase. In this way, it gives rise to four almost vertical and parallel lines, which indicate that in practice, a stabilisation of the granular material has taken place. By using the classification of the "shakedown concept" of Werkmeister [10], the material in these cases was considered to be in "range A". Therefore under these loads, according to the above 
classification, with this range, rutting is not produced in the material. On the other hand, in the same figure it was observed that for stress path $\mathbf{P 1 1}$, the increase in $\varepsilon_{1 p}(\%)$ was a little more accentuated. Here the line is now almost off the vertical, less inclined and the decrease in the rate does not produce the stabilisation of permanent deformation, so the material may possibly behave as in "range B". In the line that represents stress path P5, at first the increase in $\varepsilon_{1 p}(\%)$ is even more accentuated. Curiously, it would seem that a slight stabilisation was produced in the central zone (between $\varepsilon_{1 p}=1.4 \%$ and $\varepsilon_{1 p}=1.6 \%$ ), with $\varepsilon_{1 p}(\%)$ increasing considerably at the end of the curve. Here, the material is in "range C", especially at the end of the line. Finally, for the five stress paths P4, P10, P7, P9 and P8 the material behaves between "range $\boldsymbol{B}$ " and "range $\boldsymbol{C}$ ". However, when $N$ increases it gives rise to a sharp increment in $\varepsilon_{1 p}(\%)$, clearly passing over to "range $C$ ", where rutting will be produced.

\section{Goodness-of-fit results}

Table 3 shows all the values for the parameters of equations 1,2,3,4 as well as the determination coefficients $\mathbf{R}^{2}$. In figure 4 the values predicted for equation 1 (Sweere model) and the laboratory data for the eleven stress paths are represented. In general, the experimental data are close to the continuous lines of the models. In this sense, the adjustment may be considered satisfactory, seeing that in all the cases the determination coefficients $\left(\mathbf{R}^{2}\right)$ yield a result of over $91 \%$. An interesting observation is that the statistical analysis of the residuals indicated that in the long term (that is, for a higher number of cycles), this equation tends to underestimate the observed values of $\boldsymbol{\varepsilon}_{1 \mathrm{p}}$. On the contrary, the determination coefficients $\mathbf{R}^{\mathbf{2}}$ of equation 2 (Wolff model) for $\mathbf{P 1}$, P2, P3, P6 and P11, do not result in values that are as satisfactory as those predicted by equation 1 . Even so, the adjustments are acceptable, ranging between 80 and $85 \%$. In the curves corresponding to stress

paths P4, P5, P7, P8, P9 and P10, the adjustment is much better, where $\mathbf{R}^{\mathbf{2}}$ is greater than $90 \%$. From the analysis of the residuals it was deduced that in the long term, equation 2 tends to overestimate the observed values of $\varepsilon_{t p}(\%)$.

On the other hand, when the non-linear regression analysis of equation 3 (non-linear model of three parameters) was carried out, a very good adjustment was seen between the estimated and observed 
values of the permanent deformation $\left(\mathbf{R}^{2}\right.$ greater than $\left.95 \%\right)$. Equation 3 also underestimates the observed values of $\varepsilon_{t p}(\%)$ in the long term.

Equation 4 (Paute model) presents $\mathbf{R}^{\mathbf{2}}$ values of higher than $85 \%$, except in the cases of stress paths P4, P7 and P10, in which the value decreases by up to $80 \%$. The values of $B$ are always negative and very small. Figure 4 it clearly shows that the values of the $A$ parameters do not represent the limit of $\varepsilon_{1 p}^{*}(\%)$. Therefore the practical values are those corresponding to $\left.2\left[\varepsilon_{1 p}^{*} 2000 q \%\right)\right]$. It is of interest to point out that in the continuous curves corresponding to equation 4 in figure 4 , the limits of accumulative permanent strain $\varepsilon^{*}{ }_{1 p}(\%)$ are very close to these practical values (except P5, P8, $\mathbf{P 9}$ and P11). In the long term, equation 4 also underestimates the laboratory values of $\varepsilon^{*}{ }_{1 p}(\%)$.

Afterwards, the values for parameters $a$ and $b$ in equation 5 were also obtained. These parameters were different for the eleven stress paths. So, the second part of the Paute model does not accurately express the variations of parameter $A$ with respect to stress.

Finally, parameters $a$ and $b$ in equation 6 (Lekarp model) are $1.30 \times 10^{-2}$ and 5.40 respectively. The $\mathbf{R}^{2}$ coefficient is equal to $91.63 \%$. For this model there is a good fit between the observed values and those predicted by the theoretical model.

\section{Plastic deformation (rutting)}

Rutting is produced by a single axle load of $130 \mathrm{kN}$ with single tires upon section 4131 . To estimate the rut depth, the highest values of the permanent deformation were taken into account; that is to say, those corresponding to stress paths P8 (for equations 1, 2 and 3) and P5 (for equation 4). This depth is simply the product of the predicted accumulative permanent strain $\varepsilon_{1 p}$ and the thickness of the granular material $(200 \mathrm{~mm})$, where $\varepsilon_{1 p}=\varepsilon_{1 p}(\%) / 100$ was obtained with equations 1 , 2, 3 and 4. The second part of the Paute model was rejected because it was not fulfilled in this case, as discussed earlier. The Lekarp model was not used either because it does not take into account the number of cycles in the long term.

On the other hand, it should be mentioned that under the Spanish pavement regulations [2] it is foreseen that 50 heavy vehicles per day (pavement section 4131) will be supported in the service lane. In view of this information, this traffic flow was considered in order to estimate (by means of equation 7) the number of $130 \mathrm{kN}$ axles in the service traffic lane during the analysis period [11]: 


$$
N_{T}=A A D T_{H V} \times C \times A \times 365
$$

where:

$N_{T} \quad=$ Number of standard loads of $130 \mathrm{kN}$ during the analysis period.

$A A D T_{H V}=$ Annual average daily heavy traffic in the service lane, during the analysis period.

$C \quad=$ Traffic growth factor.

A $=$ Equivalence factor of a heavy vehicle on standard axles.

With an annual estimated growth of $2 \%$ for a design period of 20 years the result is a $C$ equal to 24.30. On the other hand, $A$ is equal to 0.70 [11]. Under these premises $N_{T}$ is equal to $3.10 \times 10^{5}$ load cycles. Thus, in the design period of the pavement, rut depths of $4.73 \mathrm{~mm} ; 5.87 \mathrm{~mm} ; 5.01 \mathrm{~mm}$ and $2.10 \mathrm{~mm}$ are predicted respectively with equations $1,2,3$ and 4 .

\section{Discussion of the results}

From the results of the triaxial tests it can be deduced that the increase in permanent deformation does not behave in the same way under all load conditions. In the curves with stress paths P1, P2, $\mathbf{P} 3$ and $\mathbf{P 6}$, a very slow increase in $\varepsilon_{1 p}(\%)$ is produced, virtually giving rise to stabilisation ("range $\boldsymbol{A}$ " of Werkmeister). In the curve with stress path $\mathbf{P 1 1}$, the increase in $\boldsymbol{\varepsilon}_{1 p}(\%)$ is a little more accentuated ("range B" of Werkmeister). On the other hand, in the curves with stress paths P4, P5, $\mathbf{P 7}, \mathbf{P 8}, \mathbf{P 9}$ and $\mathbf{P 1 0}$, the increase is much more accentuated and the stabilisation of the material is not observed ("range C"). This result is due to the fact that when the values of the deviator stresses approach the failure envelope of the material, a clear acceleration in the increase of $\varepsilon_{1 p}$ is produced. Employing equations 1, 3 and 4 a better fit is obtained for the stress conditions of P1, P2, P3, P6 and $\mathbf{P 1 1}$, whereas in equation 2 the $\mathbf{R}^{\mathbf{2}}$ coefficient is greater in the cases of $\mathbf{P 4}, \mathbf{P 5}, \mathbf{P 7}, \mathbf{P} \mathbf{8}, \mathbf{P} \mathbf{9}$ and P10.

Equation 1 (Sweere model) has a very good fit, although when the granular material is found in "range C" (starting from approximately $10^{5}$ cycles) it underestimates the laboratory values of the deformation as can be seen in figure 4. As pointed out previously, this model has the disadvantage of making predictions set under the laboratory values for a greater number of axles.

When the material is in "range C" (fig. 4), equation 2 (Wolff model) is better adjusted starting from $10^{4}$ cycles. The main discrepancies between the predicted and observed values are manifested during the first $10^{3}$ cycles. Nevertheless, it is necessary to proceed with caution when making long term predictions, since this model is very conservative. 
Equation 3 (non linear model of three parameters) is the one that presents the best R-square values. Nonetheless, this model has the same drawback as equation 1, i.e. it underestimates the observed values of $\varepsilon_{1 p}(\%)$ when the material is in "range $C$ ". Therefore, it also has the disadvantage of offering lower long term strain values than those of laboratory.

Equation 4 (Paute model) also underestimates the laboratory values for a large number of cycles in "range $C "$ ". Furthermore, according to table 3, the values of $B$ are consistently low and negative. The values of the $A$ parameters do not coincide with the limits of permanent deformation and it was necessary to adopt the practical values, 2 [ $\varepsilon_{1 p}^{*} 20000 \%$ ], as limits of permanent deformation.

The rut depth predictions offered by equations 1,2 and 3, were found to be quite similar up to a number of cycles equal to $10^{5}$ (fig. 5). From here on, the predictions of equation 2 increase very rapidly, whereas those of equations 1 and 3 stay within the same order. As expected, the predictions of equation 4 are somewhat different because they do not take into account the permanent deformation accumulated during the first 100 cycles. In this sense, when $N=100$ cycles equations 1 , 2 and 3 predict rut depths of $3.09 \mathrm{~mm}, 3.60 \mathrm{~mm}$ and $3.18 \mathrm{~mm}$ respectively.

It is evident that by adopting the failure criterion of the Transportation Research Laboratory (rut depth of $10 \mathrm{~mm}$ in the surface of the pavement) [12], the prediction offered by equations $1,2,3$ and 4 does not exceed the maximum permanent deformation that would be considered admissible. Nevertheless, to be able to make a comparison with the aforementioned limit, it would be necessary to determine the permanent deformation in each layer (asphalt mixture layer, granular material layer and sub-grade) and sum up the results.

In cases of more than $2 \times 10^{5}$ axles, the values obtained with equation 2 keep on the safe side and therefore this law is deemed to be conservative and tends to reject materials that could be structurally valid. On the other hand, for more than $2 \times 10^{5}$ axles, equations 1,3 and 4 are nonconservative (in the sense that they predict deformations lower than those of the laboratory and consequently might admit unsuitable materials from a structural point of view).

It would be interesting to compare the results of these models with a TRL lineal rut model determined from the analysis of the performance of full-scale experimental pavements [13]. The rut model in question is: $R D=2.66+0.84 \mathrm{~N}$ and it predicts the rut depth $(R D)$ on the surface of a granular 
base pavement. Figure 5 shows that when $N=0$ the initial rut depth is $2.66 \mathrm{~mm}$ (assumed for new surfaces at the time of construction). In the design period, when $N_{T}$ is $0.310 \times 10^{6}$ rutting is equal to $2.92 \mathrm{~mm}$, but this depth includes the rutting of various materials (not only the base course). Also, it can be compared with a modification of the Asphalt Institute sub-grade strain criteria utilised by Deacon et al [14]. According to these authors, when the compressive strain $\left(\varepsilon_{v}\right)$ at the top of the sub-grade is equal to $7.90 \times 10^{-4}$, the rut depth contributed by unbound layers is assumed to accumulate as follows: $R D=0.052 N^{0.372}$, where the coefficients are experimentally determined from least square analyses using the WesTrack data. The increase of rutting in the latter model is more accentuated, thus in the design period rutting is equal to $5.72 \mathrm{~mm}$ (figure 5).

In the long term predictions provided by the TRL and WesTrack equations are higher than the predictions of equations 1, 3 and 4 and lower than those of equation 2 . According to these results, it would also seem that in the long-term, equation 2 is conservative and equations 1, 3 and 4 are nonconservative (figure 5). It is important to note, however, that these rut models are based on pavement materials, designs and construction standards practised in the USA and England.

In view of the above, it would seem advisable to consider the main failure criterion to be the fact that the granular material is found in "range $C$ " owing to the number of axles and the stress level that must be supported by the pavement section. Therefore, we would have to reject the use of this material under section $\mathbf{4 1 3 1}$ because of the inadmissible plastic ruts it would produce.

\section{Conclusions}

From the results of this research the following conclusions may be drawn:

- Equations 1, 3 and 4 are models which, in the long term, predict smaller plastic deformations than those that were observed, whereas equation 2 is a model that in the long term predicts higher results than those observed.

- Equations 1, 2 and 3 predict very similar rut depths between $10^{3}$ and $2 \times 10^{5}$ cycles. From this point on, predictions diverge, with the rut depths predicted by equation 2 being very high in comparison with the ones predicted by the other equation.

- The granular material analysed was demonstrated to be unsuitable for use under section $\mathbf{4 1 3 1}$ for road pavements in Galicia. This is due to the fact that, under the stress levels it must 
support, it falls within "range C" of the "shakedown concept" classification, which indicates

that plastic ruts would be produced.

\section{References}

[1] Ministerio de Fomento. Anexo actualización PG-3. Capas estructurales de firmes. Anexo del pliego de prescripciones técnicas generales para obras de carreteras y puentes. In: Bustos; G., editor. PG-3 Anexo de actualización. Ediciones Liteam, 2002. p. 1-15.

[2] Ministerio de Fomento. Secciones de firme de la instrucción de carreteras. In: Bustos; G., editor. 6.1-IC Texto Oficial. Madrid: Ediciones Liteam, 2002. p. 1-22.

[3] Medina, L., Pérez, I., and Crespo, R. Comprobación estructural de las secciones de firme de la instrucción de Carreteras 6.1 y 6.2 IC. Revista de Obras Públicas 2002; 3457: 35-52.

[4] Sweere, G. T. H. Unbound granular bases for roads. Ph.D. Thesis, University of Delft, 1990.

[5] Wolff, H. and Visser, A. T. Incorporating elasto-plasticity in granular layer pavement design. In Proceedings of the Institution of Civil Engineers Transport 1994; 105: 259-272.

[6] Paute, J. L., Jouve, P., Martínez, J., and Ragneau, E. Modele de calcul pour le dimensionnement des chaussées souples. Bulletin de liasion des laboratories des Ponts et Chaussées 1988; 156: 21-36.

[7] Paute, J. L., Hornych, P., and Benaben, J. P. Comportement mécanique des graves non traitées. Bulletin de liasion des laboratories des Ponts et Chaussées 1994; 190: 27-38.

[8] Lekarp, F. Permanent deformation behaviour of unbound granular materials. Licentiate Thesis. Department of Infrastructure and Planning, Royal Institution of Technology, Stockholm, 1997.

[9] Lekarp, F. and Dawson, A. Modelling permanent deformation behaviour of unbound granular materials. Construction and Building Materials 1998; 12: 9-18.

[10] Werkmeister, S., Dawson, A. and Wellner, F. Permanent deformation behaviour of granular materials and the shakedown concept. Transportation Research Record 2003; 1757: 75-81.

[11] Crespo, R., and Sánchez, C. Justificación tensional de las secciones estructurales propuestas en el catálogo de firmes de autovías. Convenio de colaboración entre la Dirección General de Carreteras y el Centro de Estudios de Experimentación de Obras Públicas (CEDEX) para la revisión de las Normas 6.1I.C., 6.2-I.C. y 6.3-I.C. CEDEX. Centro de Estudios de Carreteras, 1986.

[12] Powell, W. D., Potter, J. F., Mayhew, H. C. and Nunn, M. E. The Structural Design of Bituminous Roads, Laboratory Report 1132, Transport and Road Research Laboratory, Department of Transport, 1984.

[13] Kannemeyer, L. Modelling road deterioration and maintenance effects in HDM-4. Chapter 5 Rutting of Paved Surfaces. ISOHDM. RETA 5549- REG Highway Development and Management Research. Final Report. Prepared for Asian Development Bank, 1995. p.18-19.

[14] Deacon, J. A., Harvey, J. T., Guada, I., Popescu, L. and Monismith, C. L. An Analytical-Based Approach to Rutting Prediction. Annual meeting of the Transportation Research Board (TRB) 2002, Washington, D.C. USA. 
Figure 1. Grading curve of the material




Figure 2. Stress Paths

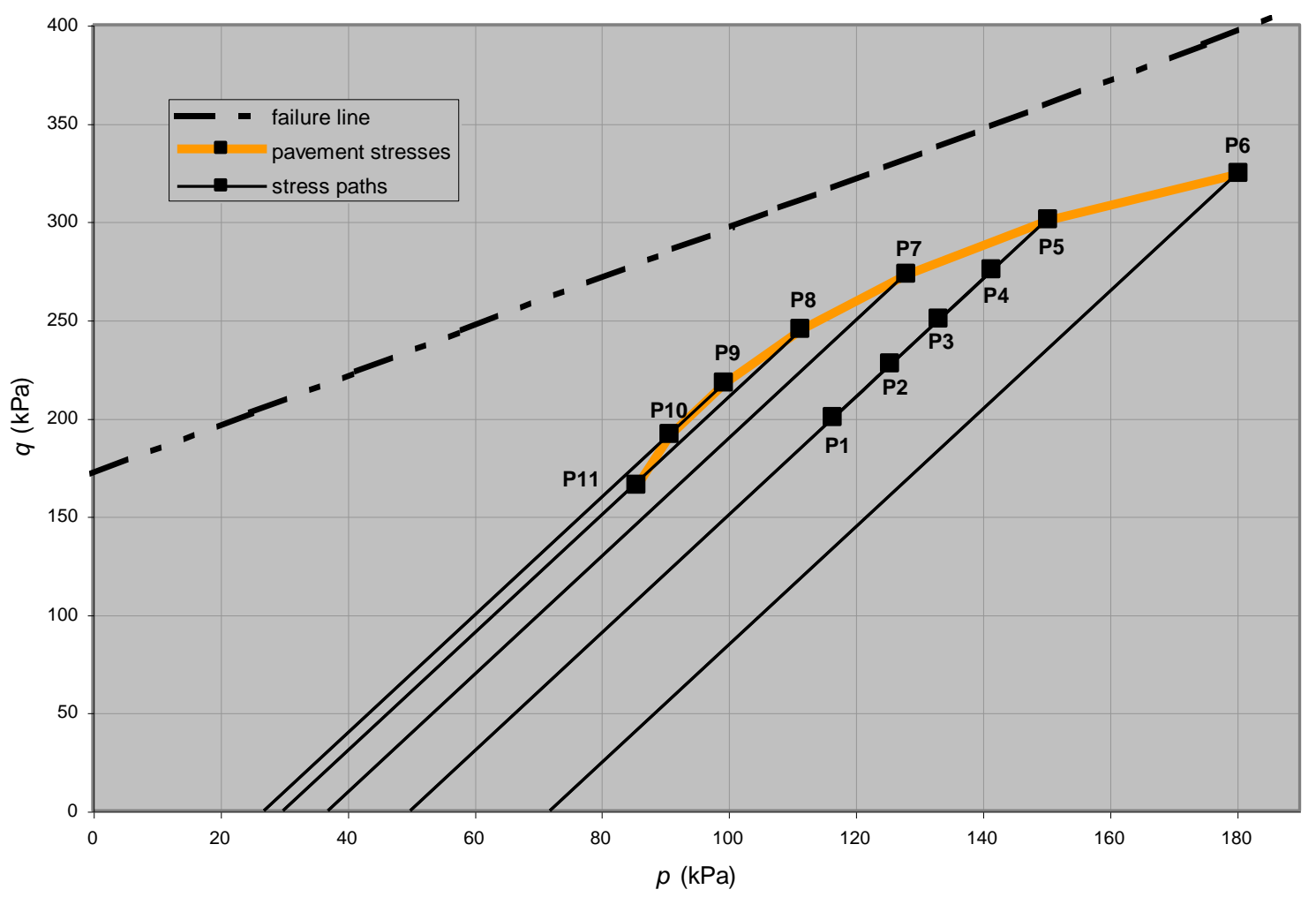


Figure 3. Cumulative permanent strain rate versus cumulative permanent strain

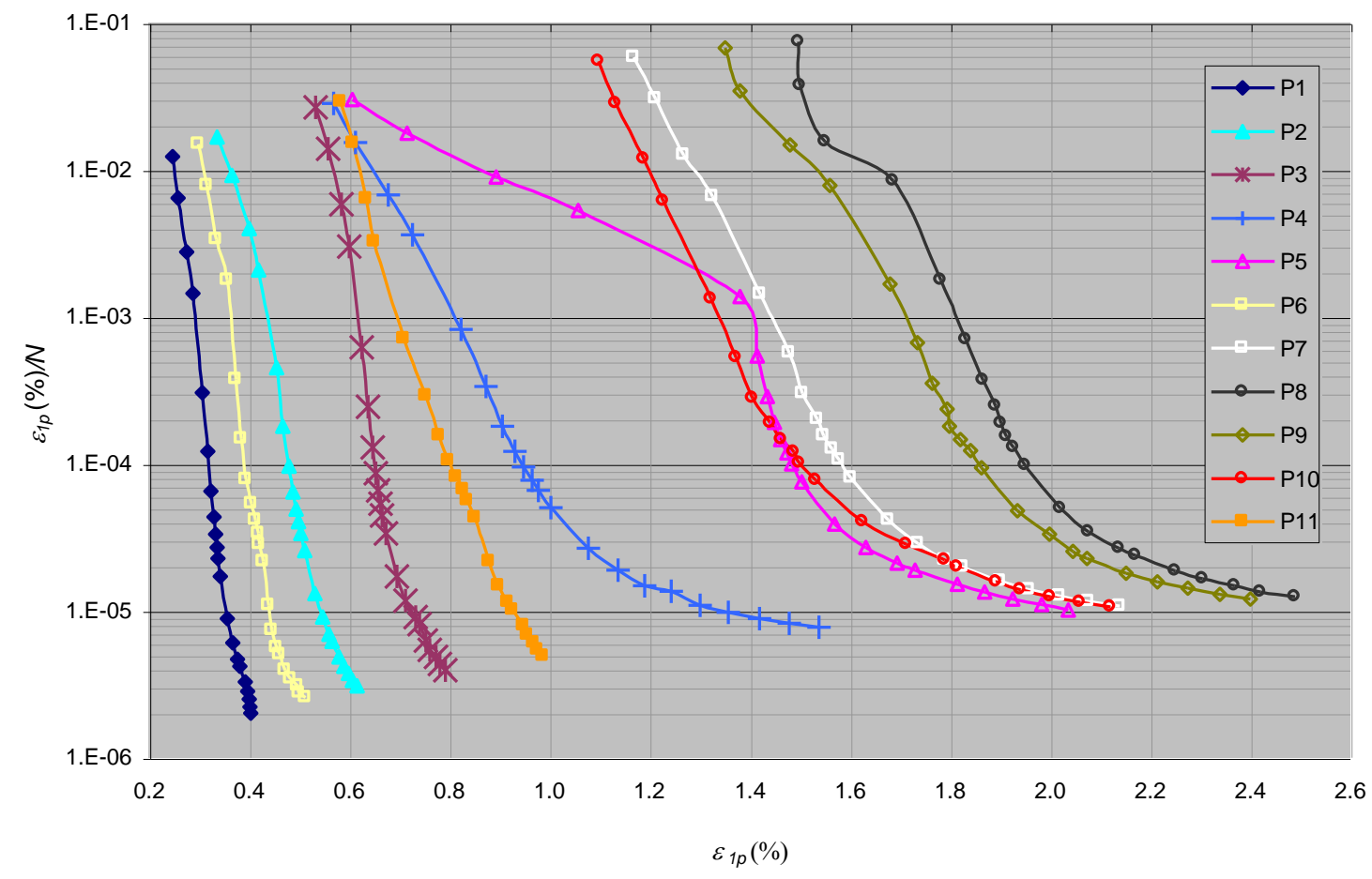


Figure 4. Permanent deformation versus load cycles
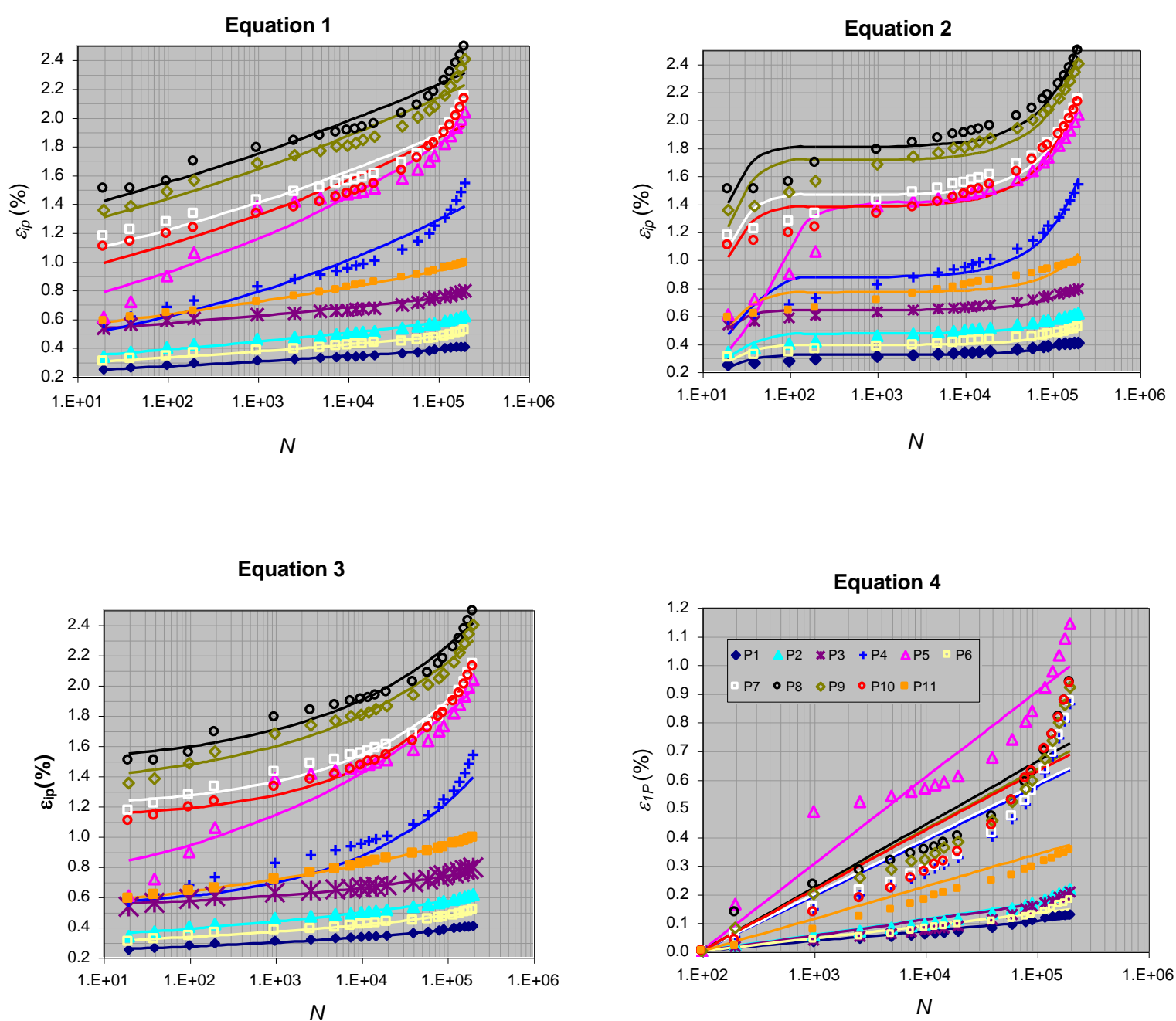
Figure 5. Prediction of rut depths

Standard error bars represent the $99 \%$ confidence interval of a mean.
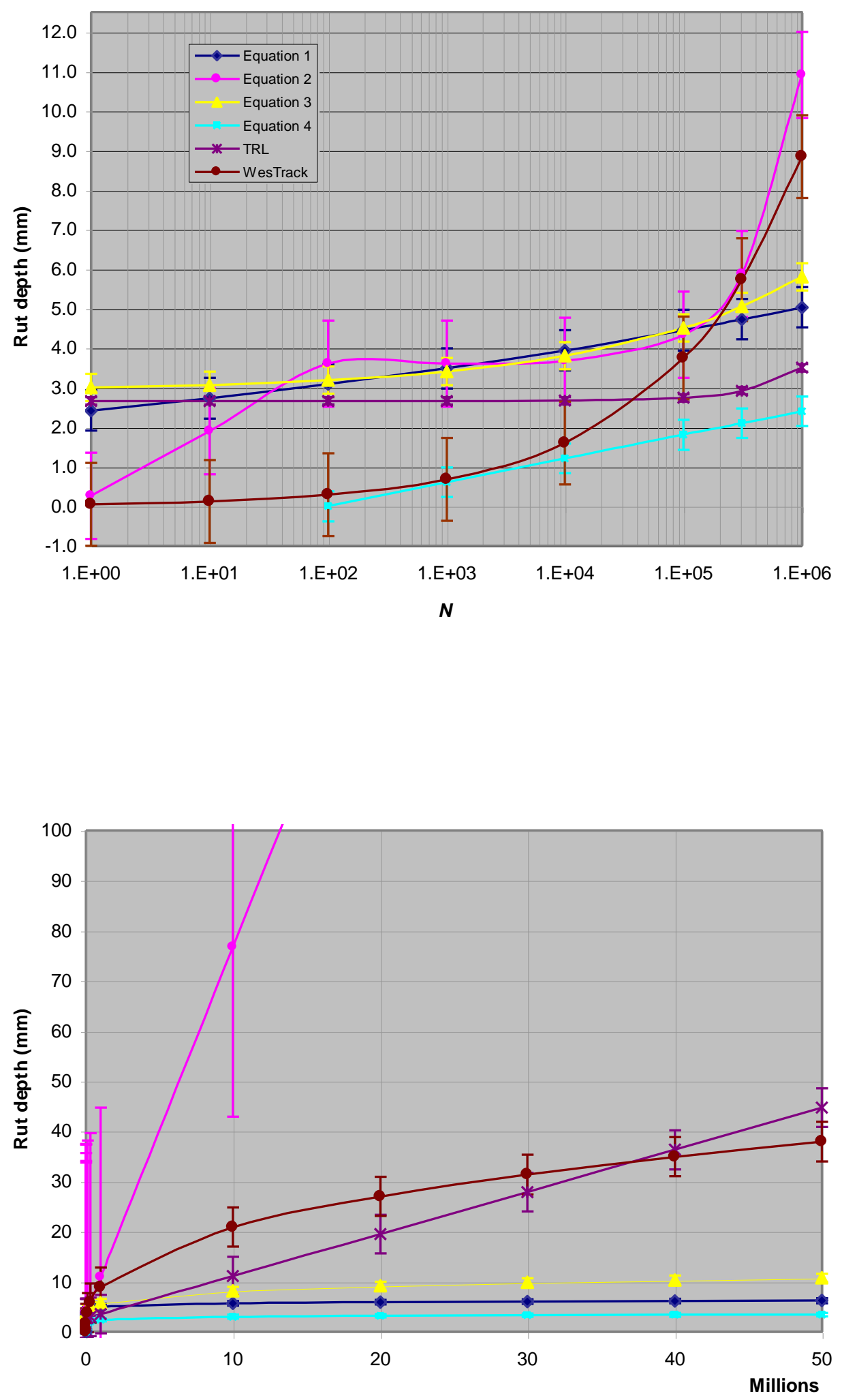

$N$ 
Table 1. Characterisation tests

\begin{tabular}{|c|c|c|}
\hline TEST & PARAMETER & RESULT \\
\hline \multirow{2}{*}{ Modified Proctor Test } & Dry density $\left(\mathrm{g} / \mathrm{cm}^{3}\right)$ & 2.3 \\
\cline { 2 - 3 } & $\begin{array}{c}\text { Optimum moisture } \\
\text { content }(\%)\end{array}$ & 6.4 \\
\hline Atterberg Limits & Non plastic & Non plastic \\
\hline Sand Equivalent & Sand Equivalent & 51 \\
\hline Los Angeles Abrasion & Coefficient $(\%)$ & 37 \\
\hline Organic material content & Proportion $(\%)$ & 0.19 \\
\hline Surface cleanness & Coefficient $(\%)$ & 1.3 \\
\hline Elongation Index & Elongation Index $(\%)$ & 3.0 \\
\hline Percentage of fractured particles & Proportion $(\%)$ & 100 \\
\hline
\end{tabular}


Table 2. Permanent deformation models

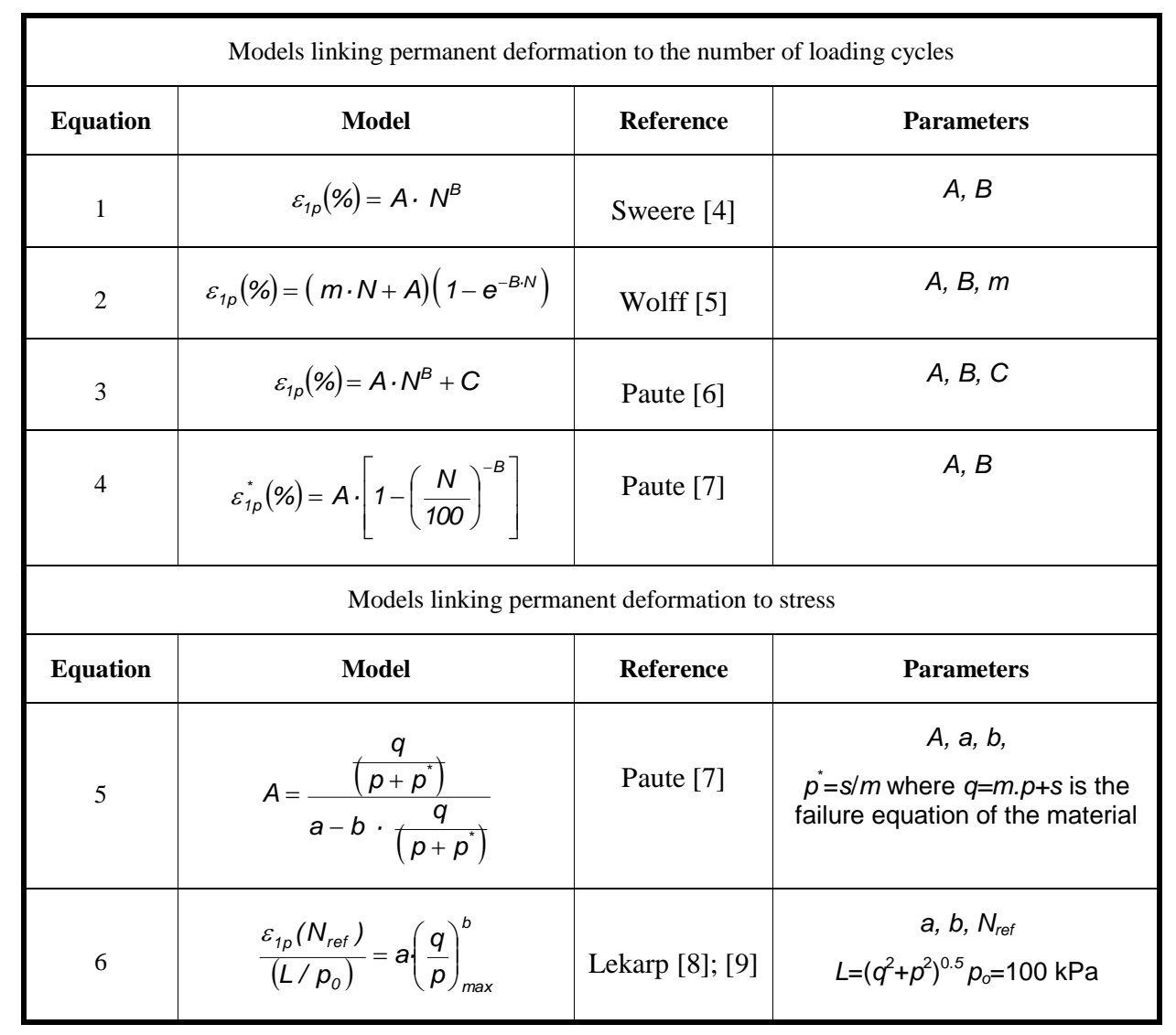


Table 3. Model parameters

\begin{tabular}{|c|c|c|c|c|c|c|c|c|c|c|c|c|c|c|c|c|c|c|c|c|c|c|c|}
\hline \multirow{2}{*}{\multicolumn{4}{|c|}{ Parameter }} & \multicolumn{4}{|c|}{$A$} & \multicolumn{4}{|c|}{$B$} & \multicolumn{4}{|c|}{$C$} & \multicolumn{4}{|c|}{$m$} & \multicolumn{4}{|c|}{$\mathrm{R}^{2}$} \\
\hline & & & & \multicolumn{4}{|c|}{ Equation } & \multicolumn{4}{|c|}{ Equation } & \multicolumn{4}{|c|}{ Equation } & \multicolumn{4}{|c|}{ Equation } & \multicolumn{4}{|c|}{ Equation } \\
\hline Stress Path & $q(\mathrm{kPa})$ & $p(\mathrm{kPa})$ & $\sigma_{3}(\mathrm{kPa})$ & 1 & 2 & 3 & 4 & 1 & 2 & 3 & 4 & 1 & 2 & 3 & 4 & 1 & 2 & 3 & 4 & 1 & 2 & 3 & 4 \\
\hline P1 & 200.00 & 116.67 & 50.00 & 0.21 & 0.32 & 0.04 & 103.09 & 0.05 & -0.06 & 0.13 & $-1.47 \times 10^{-4}$ & ---- & --- & 0.19 & --- & --- & $5.33 \times 10^{-7}$ & --- & --- & 98.07 & 85.36 & 98.86 & 93.48 \\
\hline P2 & 227.00 & 125.66 & 50.00 & 0.29 & 0.47 & 0.11 & 149.46 & 0.06 & -0.05 & 0.10 & $-1.62 \times 10^{-4}$ & ---- & --- & 0.20 & ---- & ---- & $8.44 \times 10^{-7}$ & --- & --- & 98.16 & 87.51 & 98.42 & 93.55 \\
\hline P3 & 250.00 & 133.33 & 50.00 & 0.47 & 0.64 & 0.02 & 130.15 & 0.04 & -0.08 & 0.20 & $-1.82 \times 10^{-4}$ & ---- & --- & 0.52 & --- & --- & $8.94 \times 10^{-7}$ & --- & --- & 94.83 & 86.47 & 98.02 & 92.10 \\
\hline P4 & 275.00 & 141.66 & 50.00 & 0.37 & 0.87 & 0.02 & 303.64 & 0.11 & -0.04 & 0.31 & $-2.74 \times 10^{-4}$ & --- & --- & 0.52 & ---- & ---- & $3.53 \times 10^{-6}$ & ---- & --- & 93.86 & 93.90 & 97.73 & 82.01 \\
\hline P5 & 300.00 & 150.00 & 50.00 & 0.58 & 1.40 & 0.22 & 46.07 & 0.10 & -0.01 & 0.15 & $-28.67 \times 10^{-4}$ & --- & ---- & 0.48 & ---- & ---- & $3.35 \times 10^{-6}$ & --- & --- & 94.03 & 94.03 & 95.66 & 91.38 \\
\hline P6 & 324.00 & 180.00 & 72.00 & 0.26 & 0.39 & 0.05 & 22.18 & 0.05 & -0.06 & 0.13 & $-8.67 \times 10^{-4}$ & ---- & \begin{tabular}{|c|}
--- \\
\end{tabular} & 0.23 & --- & --- & $6.78 \times 10^{-7}$ & --- & --- & 97.16 & 86.99 & 97.92 & 92.27 \\
\hline P7 & 273.00 & 128.00 & 37.00 & 0.91 & 1.46 & 0.02 & 14.82 & 0.06 & -.0 .07 & 0.30 & $-5.80 \times 10^{-3}$ & ---- & --- & 1.18 & ---- & --- & $3.61 \times 10^{-6}$ & --- & --- & 91.84 & 92.49 & 97.58 & 82.24 \\
\hline P8 & 245.00 & 112.00 & 30.00 & 1.21 & 1.80 & 0.04 & 115.81 & 0.05 & -0.07 & 0.26 & $-8.26 \times 10^{-4}$ & ---- & \begin{tabular}{|c|}
--- \\
\end{tabular} & 1.46 & --- & --- & $3.65 \times 10^{-6}$ & --- & --- & 92.37 & 90.86 & 96.67 & 86.16 \\
\hline P9 & 217.00 & 99.00 & 27.00 & 1.09 & 1.71 & 0.06 & 75.60 & 0.05 & -0.06 & 0.23 & $-1.22 \times 10^{-3}$ & ---- & --- & 1.30 & --- & ---- & $3.67 \times 10^{-6}$ & ---- & --- & 93.67 & 90.62 & 96.84 & 85.66 \\
\hline P10 & 191.00 & 91.00 & 27.00 & \begin{tabular}{|l|}
0.79 \\
\end{tabular} & 1.38 & 0.01 & 11.49 & 0.07 & -0.07 & 0.34 & $-8.09 \times 10^{-3}$ & \begin{tabular}{|l|}
---- \\
\end{tabular} & \begin{tabular}{|l|}
--- \\
\end{tabular} & 1.11 & ---- & ---- & $4.08 \times 10^{-6}$ & --- & --- & 91.68 & 92.68 & 99.01 & 80.35 \\
\hline P11 & 165.00 & 85.00 & 30.00 & 0.48 & 0.75 & 0.20 & 38.82 & 0.06 & -0.06 & 0.10 & $-1.26 \times 10^{-3}$ & ---- & --- & 0.31 & --- & --- & $1.36 \times 10^{-6}$ & --- & --- & 99.64 & 79.42 & 99.88 & 97.54 \\
\hline
\end{tabular}

